\title{
Paying People to Look at the Consequences of Their Actions
}

Daylian M. Cain ${ }^{1}$ and Jason Dana ${ }^{2}$

This version: August 15, 2012

\begin{abstract}
Prior research has suggested that people prefer to remain uncertain about the possible negative social consequences of their actions and that this uncertainty facilitates selfish behavior. Our participants played an economic game where they were uncertain about how selfish actions would affect other players; we offered participants various incentives to "look" at the potential consequences of their actions, and this reduced selfishness. Contrary to both "crowding out" and adverse selection, participants who were paid to look were more generous than participants who looked without payment. We also find that these payments can be cost-effective: small payments can lead to social welfare gains that are larger than the total cost of subsidies. Our results suggest an efficient way of changing behavior because it may be cheaper to pay someone to look at information about their social footprint-thus activating their social preferences - than it would be to directly monitor/reward prosocial behavior.
\end{abstract}

\footnotetext{
${ }^{1}$ Yale University, School of Management, 135 Prospect Street, New Haven CT, 06520, Fax: 203889 3179, Tel: 203-432-9441, Email: daylian.cain@ yale.edu

${ }^{2}$ University of Pennsylvania, Psychology Department, 3720 Walnut St., Philadelphia PA, 19104, Tel: 215-5734088, Email: danajd@ sas.upenn.edu

ACKNOWLEDGMENTS: We are grateful for comments from Shane Frederick, Barry Nalebuff, Uri Simonsohn, seminar participants at Harvard University, New York University, Rutgers, the University of Texas-Dallas, Yale University, and conference attendees at the Society for Judgment and Decision Making, Behavioral Decision Research in Management and the Allied Social Science Association annual meetings. Daylian Cain is thankful for funding from the Russell Sage Behavioral Economics Fellowship. Jason Dana is thankful for funding from the International Foundation for Research in Experimental Economics (IFREE) Small Grant program and the Goldstone Research Unit at the University of Pennsylvania. Jeff DeWitt and Jesse Marczyk provided excellent research assistance.
} 


\section{Introduction}

Most people try to avoid knowingly causing harm to others, but the emphasis is often on the word "knowingly." People may be quite willing to cause harm if they can do so in ignorance or if they can at least plausibly deny that they knew what they were doing. For example, imagine a high school American football coach who is faced with decisions about whether to play athletes who show signs of concussions. Such a coach may bench a key player and risk losing a big game before exposing the player to known risks of brain injury. One might say that this coach cares about his players' welfare since the coach makes sacrifices for his players' health. But imagine a situation where the coach is unsure whether a player has a concussion. Would the coach want to know? If there were simple tests for concussions, would the coach want to look at the results? Might he even go out of his way to avoid finding out whether a player had a concussion?

This notion of taking pains to avoid learning about the social consequences of one's actions has been explored through several experiments on "strategic ignorance"3 (Dana, Weber, and Kuang 2007; Larson and Capra 2009; Grossman 2010; van der Weele 2011), in which participants refuse costless information (about the correlation between their payoffs and others' outcomes) so that they can be more selfish. For example, suppose that the aforementioned football coach could easily test for concussions but preferred not to look at such tests. It is difficult to explain the coach's behavior-the benching of players with known concussions yet not wanting to know if the players have concussions-with standard social preferences theories in which agents want to be prosocial because of genuine altruism, equity, self-image, social image, warm glow, and so on. If the coach truly wanted to promote such things, he would want to know the results.

We replicate prior experimental findings of strategic ignorance. We also show, however, that paying people small amounts of money to resolve uncertainty about-i.e., to "look" at- the social consequences of their actions can reduce strategic ignorance. Furthermore, we show that the effect of these payments is not merely due to increased awareness of social consequences. Even conditional on looking, participants paid to look are more generous than those who look without payment.

Our results speak to several bodies of literature. A growing empirical and theoretical literature seeks to understand the economic consequences of strategic ignorance (Grossman 2010; van der Weele 2012) or duty-bound rational ignorance (Nyborg 2011), in which decision-makers refuse information to avoid feeling obligated to engage in prosocial action. Offering payment for consuming information suggests a mechanism for quantifying the value of such ignorance to decision-makers. Paying people to consume potentially guilt-inducing information also speaks to literature on how extrinsic incentives can

\footnotetext{
${ }^{3}$ This type of duty-bound strategic ignorance could be distinguished from strategic ignorance as a disciplining device (Carrillo and Mariotti 2 2000), in which agents with inconsistent time preferences can sometimes commit to future action by ignoring costless information.
} 
have paradoxical effects. This is particularly true when intrinsic motivations are in place or, as in the case of prosocial behavior, when extrinsic incentives have not traditionally been used (Gneezy and Rustichini 2000a; 2000b; Gneezy, Meier, and Rey-Biel 2011). One might have anticipated that our payment mechanism would "crowd out" intrinsic motivations and make people less generous. Our method is innovative, however, in that we intervene at an earlier point in the decision chain. Rather than paying people to be generous, we are merely paying them to be informed, and the latter could behave differently in regard to crowding out, which is an idea we briefly discuss in the discussion section.

Finally, the literature on libertarian-paternal nudges (Thaler and Sunstein 2008) suggests that interventions can steer decision-makers toward better choices without eliminating any options, especially when decision-makers would otherwise exhibit bounded rationality or bounded willpower. Our payment to look is like a nudge for people who can be described by the third pillar of behavioral economics, bounded self-interest (Mullainathan and Thaler 2001). In this vein, several empirical and theoretical studies explore the phenomenon of agents "sorting out" of situations that will make them feel guilty about taking selfish actions (see Dana, Cain, and Dawes 2006; Lazear, Malmendier, and Weber 2012; Dillenberger and Sadowski 2010). Our payments are a nudge toward generosity because they encourage people to sort into a situation that activates social preferences without otherwise restricting them from acting selfishly.

\section{Experiment}

The participants consisted of 444 students at the University of Pennsylvania who were recruited by online advertising to participate in paid experiments. Experimental sessions were conducted in groups of 8 to 18 participants. Participants were randomly assigned to the anonymous roles of sender and receiver. The instructions referred to the sender and receiver roles only as Player X and Player Y, respectively. All stimuli and instructions were presented via computer interface, and instructions were also read aloud by the experimenter. Before making choices, all participants had to pass a quiz evaluating their understanding, and it was publicly announced when the entire group had answered all questions correctly.

The participants played a game similar to that discussed by Dana, Weber, and Kuang (2007), the structure of which is depicted in Figure 1. In the game, senders faced a choice between receiving $\$ 6$ or $\$ 5$ for themselves, with this choice having uncertain effects on the payoffs to the receiver. In the conflicted payoffs case $[(\$ 6, \$ 1)$ vs. $(\$ 5, \$ 5)]$, choosing $\$ 6$ for oneself left the receiver with $\$ 1$, while choosing $\$ 5$ left the receiver also with $\$ 5$. In the aligned payoffs case $[(\$ 6, \$ 5)$ vs. $(\$ 5, \$ 1)]$ the decision was easy because choosing $\$ 6$ for oneself was also best for the receiver, who would get $\$ 5$, whereas choosing $\$ 5$ for oneself left the receiver with $\$ 1$, leaving both parties worse off. A coin flip prior to the session 
determined whether the payoffs were conflicted or aligned. Although the coin flip and payoff possibilities were publicly announced, the results of the coin flip were not. Senders could freely and privately look at which payoff state they were assigned (aligned or conflicted) by clicking a small button on the right side of the screen marked "Reveal Payoffs." The sender could, however, choose his or her payoff without revealing the payoff state. Because the reveal decision is private, a receiver who ended up with $\$ 1$ would not know whether the sender knowingly chose this payoff $(\$ 6, \$ 1)$ or chose it in ignorance $(\$ 6, \$ ?)$. To maintain anonymity, receivers also made hypothetical choices while senders made their choices.

Prior studies using similar payoff structures have shown that, when forced to look at conflicting payoffs (i.e., with certainty that payoffs conflicted), a majority of senders are generous (Dana, Weber, and Kuang 2007; Larson and Capra 2009; Grossman 2010; van der Weele 2011). From this, one might think that ignorance about payoffs should not matter: a selfish sender should still remain selfish, while a sender who actually wants to be generous when the payoffs are conflicting has nothing to lose by revealing. If one wants to be equitable, one will reveal payoffs to see whether payoffs conflict. However, the prior studies find that a large number of senders may remain ignorant and, ultimately, the majority choice is selfish when the true payoffs are conflicting. Note also that selfish choices have a relatively large social consequence in this environment: going from $\$ 5$ to $\$ 6$ gains $\$ 1$ for the self, but it costs the other person $\$ 4$, thus costs the dyad $\$ 3$ net, for a threefold reduction in social welfare. Therefore, we wanted to learn whether various subsidies for resolving uncertainty will reduce strategic ignorance and efficiently increase social welfare, i.e., whether such subsidies will increase total social welfare by more than their cost.

$<$ Figure 1 here $>$

We focus our analyses on senders $(n=222)$ because only their choices were consequential. Each session was arbitrarily assigned to 1 of 5 different conditions. Four of these conditions contained various incentives to click the reveal button. The game as described above, in which no payment for clicking "Reveal" was offered, served as the baseline (unpaid) condition $(n=43)$. In addition, two pay-to-look conditions provided a positive subsidy for clicking the reveal button. These conditions differed from the baseline only in that: 1) a sentence was added to the general instructions explaining the payment ("If Player X chooses to reveal the game, Player X will receive \$_ in addition to whatever payment Player X receives from the game, regardless of what Player X chooses after that."), and 2) the text on the reveal button was changed ("Reveal game and get $\$ \_$_). The payments in these conditions were $\$ .25(n=48)$ and $\$ 1(n=41)$. There was a "Tom Sawyer" condition (named after the fictional character who charged another boy for the "opportunity" to paint a fence), in which the sender had to pay $\$ .25$ to reveal $(n=37)$. Finally, to examine whether payments affect sender behavior because of wealth effects or other effects of 
receiving a "bonus" payment, a simple payment condition $(n=48)$ was used. In this condition, all participants were instructed that, in addition to anything earned in the game, senders would be paid an additional \$.25 just for playing the game. Senders in the simple payment were thus equated in wealth to revealers in the $\$ .25$ pay-to-look condition and were similar in terms of receiving a bonus in addition to the payments in the game matrix.

The rationales behind the payment amounts are as follows. The Tom Sawyer payment was instituted due to the fragile nature of strategic ignorance (Grossman 2010). For example, it could be that the offer of payment will cure strategic ignorance simply by making it salient to the sender so that the amount of the payment itself does not matter; in fact, charging to look might normatively suggest that other people dislike not knowing what the payoffs are. The rationale for the $\$ 1$ payment is that, even if senders feared revealing conflicted payoffs (assuming that this would compel them to give up \$1), they could be left financially no worse off by revealing than by simply choosing $\$ 6$ in ignorance. The $\$ .25$ option, on the other hand, allowed senders to take a small payment that might leave them (-\$.75) worse off for having looked.

\section{Results}

Across all conditions, every sender who did not reveal $(n=89)$ chose $\$ 6$, and every sender who revealed and faced aligned payoffs $(n=63)$ also chose $\$ 6$. In some ways, this result is unsurprising; it makes little sense for senders who have not revealed to choose $\$ 5$ because it forgoes $\$ 1$ and has no expected upside for the receiver, thus making \$6 stochastically dominant. Similarly, it was dominant for a sender who revealed aligned payoffs to choose the socially efficient $(\$ 6, \$ 5)$ option. The fact that $100 \%$ of these senders obeyed dominance in their choices suggests that they were reasonably motivated and that the instructions were clear.

\subsection{Effects of Payment on Revealing}

Table 1 displays, for each condition, how many senders chose to reveal and, when these revealers faced conflicting payoffs, what they chose. We note first that the proportions in our baseline condition closely resemble results from prior studies using similar methods. ${ }^{4}$ Perhaps unsurprisingly, senders in the pay-to-look conditions revealed more often than senders in the unpaid baseline condition and more often than the charge-to-look Tom Sawyer condition. The probability of a sender revealing appears relatively linear in this range: For the $\$ 1$ payment, 88\% (35/4) revealed; for the $\$ .25$ payment, 77\% (37/48) revealed; for unpaid, 63\% (27/43) revealed; and for $-\$ .25$ (Tom Sawyer), 24\% (9/37) revealed, yielding a

\footnotetext{
${ }^{4}$ In Dana, Weber, Kuang 2007, 56\% revealed (without payment), leading to an overall rate of $38 \%$ generosity. Conditional on looking at conflicted payoffs made for a small sample (of 8), where $75 \%$ chose $\$ 5,5$.
} 
Pearson correlation between looking and amount of payment of $.38(n=169, p<.001)$. The simple $(\$ .25$ wealth-effect) payment condition did not appear to have a similar effect on revealing, with only $47 \%$ $(25 / 53)$ senders revealing, a significantly lower proportion than in the $\$ .25$ pay-to-look condition $\left(\chi^{2}=\right.$ $9.51, p<.01)$; this result suggests that the effects of payment on revealing are not merely due to wealth effects.

\subsection{Generosity as a Function of Payment}

Paying people to reveal ought to increase revealing, and it does, but our main question was how payment affects generosity. Senders in the pay-to-look conditions were more likely to split the money equally $(\$ 5, \$ 5)$ when payoffs were conflicted than were senders in the baseline condition: for the $\$ 1$ payment, 53\% (10/19) chose an equal split; for the $\$ .25$ payment, 65\% (17/26) chose an equal split; for unpaid, 27\% (6/23) chose an equal split; and for the Tom Sawyer charge, 17\% (3/18) chose an equal split. The rates of choosing an equal split in the $\$ .25$ condition were significantly higher than in both the baseline $\left(\chi^{2}=7.57, p<.01\right)$ and the Tom Sawyer $\left(\chi^{2}=10.94, p<.01\right)$ conditions, while only the Tom Sawyer condition $\left(\chi^{2}=5.73, p=.02\right)$ differed significantly from the $\$ 1$ condition, the comparison of the $\$ 1$ condition with the baseline $\left(\chi^{2}=3.11, p=.08\right)$ falling short of significance levels. As with revealing, the effects of payment on choosing an equal split do not appear to reflect mere wealth effects. When facing conflicted payoffs, the proportion of senders in the $\$ .25$ simple payment condition who chose an equal split was $26 \%$ (7/27), significantly lower than in the $\$ .25$ pay-to-look condition $\left(\chi^{2}=8.32, p<.01\right)$. Overall, senders were more generous when paid to look: the combined rate of giving in the pay-to-look conditions was significantly higher than the combined rate of giving in the baseline and Tom Sawyer conditions $\left(60 \%\right.$ vs. $\left.21 \% ; \chi^{2}=13.32, p<.01\right)$.

Let us now consider sender behavior conditional on revealing conflicted payoffs, in part to understand how much of the increased generosity was simply due to more senders looking. Senders in the pay-to-look conditions were not only more likely to reveal payoffs but were somewhat more likely to be generous when faced with conflicting payoffs. The proportion that chose the equal split conditional on revealing was higher in the $\$ .25$ condition $(77 \%, 17 / 22)$ and $\$ 1$ condition $(67 \%, 10 / 15)$ than in the baseline condition $(44 \%, 6 / 14)$ and the Tom Sawyer condition $(50 \%, 3 / 6)$. Breaking the sample up in this way yields small sample sizes for comparison, particularly for the Tom Sawyer condition, where few senders revealed payoffs: among the individual comparisons, only the $\$ .25$ vs. baseline condition achieved significance $\left(\chi^{2}=4.39, p<.05\right)$. Overall, however, senders were more generous conditional on revealing when paid to look: the combined rate of choosing an equal split after revealing in the pay-tolook conditions was significantly higher than the combined rate of choosing an equal split in the baseline and Tom Sawyer conditions $\left(\chi^{2}=4.366, p<.05\right)$. One problem with including the Tom Sawyer condition 
in this analysis is that senders in that condition were faced with the prospect of making (net) less than the receiver by revealing and splitting equally $(\$ 4.75, \$ 5)$ and, thus, may have chosen $\$ 6$ due to their disadvantageous inequity aversion (Fehr and Schmidt 1999). When the analysis is repeated contrasting the combined pay-to-look conditions with only the baseline, the difference in choosing an equal split remains significant $\left(\chi^{2}=4.03, p<.05\right)$.

This result is the opposite of what one might have predicted on the basis of crowding out; paying people to look did not remove their intrinsic taste for giving. It is also contrary to what we might have expected from adverse selection: those who could have looked for free were less generous than the group that apparently included senders who merely looked because they were paid. We do not wish to overinterpret the significance of these effects because a change in a few senders' behavior could have placed the effects above significance levels. We merely want to point out that the effects we found ran in a direction contrary to what one might have predicted a priori: among only people who looked, those who were paid to look gave more. This increased generosity is not entirely consistent with wealth effects, as senders in the simple payment condition $(54 \%, 7 / 13)$ chose the even split less often than those in the $\$ .25$ pay-to-look condition $(77 \%)$, although this comparison is not significant $\left(\chi^{2}=2.08, p=.15\right)$.

\subsection{Social Return on Investment}

Overall, the results suggest the possibility of efficient payment for looking at one's social footprint, although it did not appear that more pay was always better. To quantify the social return of such a payment, consider our most efficient condition, the $\$ .25$ pay-to-look. Given the proportions we observed and even assuming a one-price environment where the subsidy must be offered to everyone (recall also that, $50 \%$ of the time, payoffs will be aligned anyway and welfare cannot be improved and thus the subsidy is wasted), payment in this environment yielded an expected increase in social welfare of $\$ 2.97$ for every \$1 spent, or a 197\% return on investment. On average, this increase in social welfare from paying to look did not transfer wealth from senders. Even in the $\$ .25$ pay-to-look condition, in which payment-to-look was lowest and giving was highest, the average sender's earnings from the game (\$5.87) were almost identical to the average sender's earnings in the no-pay baseline (\$5.86). If we consider only those senders who happened to face conflicting payoffs, however, senders made less, on average, when offered the subsidy (\$5.54) than when not (\$5.73). In expectation, however, our payments did not leave senders worse off financially. We leave it to future research to investigate non-financial payoffs, e.g., whether and when the emotional pain of senders' being nudged into looking at their social footprint makes them worse off or is socially inefficient. 


\section{General Discussion}

Our results suggest that paying people to consume costless information about the social consequences of their actions can lead to large increases in prosocial behavior. These payments combated strategic ignorance on two levels. First, participants who were paid to look were more likely to resolve uncertainty about the correlation between their payments and another subject's payment. Second, this increase in looking led to more generosity. The added generosity was not merely due to increased awareness; we found modest evidence that those who were paid to look were actually more generous than those who looked but were not paid. This finding is in contrast to what might have been predicted by adverse selection; even though the payment attracted several people who looked merely because they were paid to do so, the rate of generosity was higher overall when those people were included. Such payments can also be socially efficient. Our participants had the opportunity to choose in ignorance, but a small payment for revealing information was enough to drastically increase generosity. When generosity creates a net social gain over selfishness, we demonstrated that it is possible for gains to exceed the cost of subsidies. That is, our payment had a positive multiplier.

Paying people to look at their social footprint and having them regulate themselves might be cheaper and less paternalistic than trying to directly monitor and incentivize prosocial behavior. Perhaps, encouraging people to become informed and make their own decisions does little to undermine the intrinsic motivation to be prosocial (Gneezy and Rustichini 2000a 2000b) and, thus, may not be as easily crowded out. Under our payment scheme, participants could not look for free even if they wanted to. However, generosity flourished, at least for one period. A question that remains is whether such payments crowd out generosity (or looking) in the long run, especially if the payments are removed. Conversely, being aware of one's social footprint may become a habit that lasts beyond the intervention (Charness and Gneezy 2009).

From a policy perspective, there are several ways to conceptualize payment for consuming information. Payment for looking can be thought of as compensation for guilt. The strategic ignorance literature suggests that some information about the social consequences of one's action is welfaredecreasing and, thus, people do not want it. Similarly, recent field studies have found that the targets of charitable requests experience a loss of welfare and will take costly action to avoid being asked (DellaVigna, List, and Malmendier 2012; Andreoni, Rao, and Trachtman 2011). Our payment for looking could be seen as similar to a payment for "being willing to be asked" (in this case, taking a 50/50 chance that one's payoffs conflicted). Recall that, when our participants were paid to look, they tended to be even more generous than people who were willing to look without being paid. This result suggests a possible advantageous selection: those who are crowded in by the payment are more likely to be generous types when informed. 
The notion of advantageous selection with respect to payment for looking suggests interesting possibilities. Consider the example of blood donation. One problem with cash compensation for donation is that it can attract low-quality donations from so-called "skid row donors" (Titmus 1969) who otherwise would not donate. By contrast, small incentives for people to learn about blood shortages and the donation process should be less likely to attract low-quality donations: skid row donors might take the payments to look (at the need for donations) but would not then donate for free. These incentives would be highly effective in the case of advantageous selection, for example, if many of the people who take pains to remain uninformed are the very same people whose sympathies would be most evoked.

In cases like our experiment, where a payment for looking at one's social footprint has positive spillover for others, it could also be thought of as a Pigouvian subsidy (i.e., it promotes activity with positive externalities). For example, somehow paying people to be tested for sexually transmitted diseases or to receive feedback about the strain on the electrical grid could lead people to alter their behavior in ways that benefit others. Furthermore, it may be cheaper and more pragmatic, e.g., to pay people to know their HIV status so that they better regulate themselves, rather than to try to monetize actual safe sex practices.

Payments to look at test results, it is hoped, attract at-risk individuals to become tested-the very ones who are afraid to look at their test-results. Furthermore, such payments also undermine excuses for not knowing one's test results: Anyone who can claim to be risk-free still should be getting tested, if only to get paid. In the case of infectious diseases, anyone who infects another person has more difficulty in claiming ignorance when it is known that people are paid to know their status. Of course, we are being speculative here. At the least, our results suggest that offering subsidies to look at the consequences of one's own actions can efficiently encourage people to behave prosocially once it becomes common knowledge that "people should know better." 


\section{References}

Andreoni, J., Rao, J., Trachtman, H. (2011). Avoiding The Ask: A Field Experiment on Altruism, Empathy, and Charitable Giving. NBER working paper No. 17648.

Carrillo, J.D., T. Mariotti. (2000). Strategic ignorance as a self-disciplining device. Review of Economic Studies, 67, 529-544.

Charness, G., U. Gneezy. 2009. Incentives to exercise. Econometrica 77(3) 909-931.

Dana, J.D., D.M. Cain, R.M. Dawes. 2006. What you don't know won't hurt me: Costly (but quiet) exit in a dictator game. Org. Beh. and Hum. Decision Proc. 100 193-201.

Dana, J., R.A. Weber, J.X. Kuang. 2007. Exploiting moral wiggle room: Experiments demonstrating an illusory preference of fairness. Econ. Th. 33 67-80.

DellaVigna, S., J.A. List, U. Malmendier. (2012). Testing for altruism and social pressure in charitable giving. Quarterly Journal of Economics, 127, 1-56.

Dillenberger, D., P. Sadowski. Forthcoming. Ashamed to be selfish. Theoretical Econ.

Fehr, E., K.M. Schmidt. 1999. A theory of fairness, competition, and cooperation. Quar. J. Econ. 114(3) $817-868$.

Gneezy, U., A. Rustichini. 2000a. A fine is a price. J. Leg. Stud. 29(1), part 1, 1-18.

Gneezy, U., A. Rustichini. 2000b. Pay enough or don't pay at all. Quar. J. Econ. August 791-810.

Gneezy, U., S. Meier, P. Rey-Biel. (2011). When and why incentives (don't) work to modify behavior. Journal of Economic Perspectives 25 191-210.

Grossman, Z.J. (2010). Strategic ignorance and the robustness of social preferences. Working paper, University of California-Santa Barbara Dept. of Economics, Santa Barbara, CA.

Larson, T., M. Capra. 2009. Exploiting moral wiggle room: Illusory preference for fairness? A comment. Judgment and Dec. Making 4(6) 467-474.

Lazear, E., U. Malmendier, R. Weber. 2012. Sorting, prices, and social preference. American Economic Journal: Applied Economics, 4, 136-163.

Mullainathan, S., R. Thaler. 2001. Behavioral economics. International Encyclopedia of Social Sciences. 1094-1100. Pergamon Press.

Nyborg, K. (2011). I don't want to hear about it: Rational ignorance among duty-oriented Consumers. Journal of Economic Behavior and Organization, 79, 263-274.

Thaler, R., \& C. Sunstein. (2008). Nudge: Improving decisions about health, wealth, and happiness. New Haven: Yale University Press.

Titmuss, R. (1970). The gift relationship: From human blood to social policy. The New Press.

Van der Weele, J. (2011). The bliss of ignorance: Why we choose not to know. Working paper, Goethe University Frankfurt. 
Figure 1: Experimental Interface (\$.25 Pay-to-Look Condition)

To make your choice without revealing, click the button for A or B indicating your choice in the table below. If you wish to reveal which of the two games is actually being played, click "reveal game".
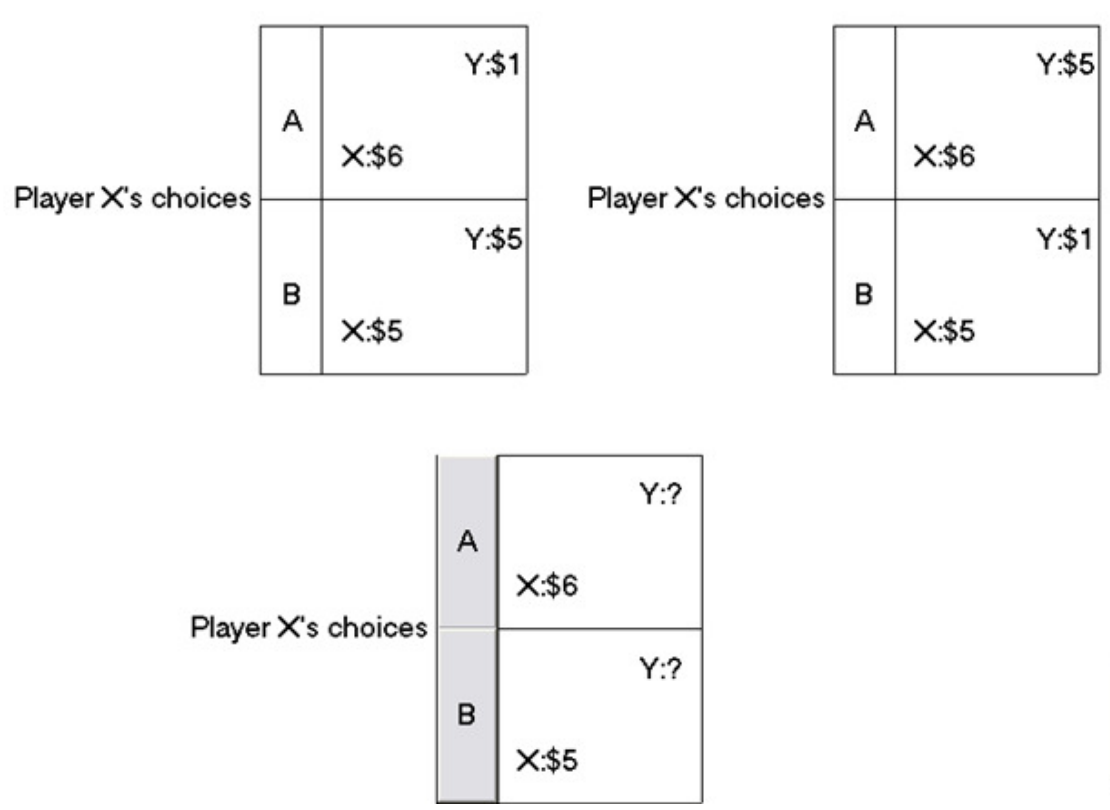
Table 1: Revealing and Giving, by Condition

\begin{tabular}{lccccc} 
& $\begin{array}{c}\text { \$1 pay } \\
n=41\end{array}$ & $\begin{array}{c}\mathbf{\$ . 2 5} \text { pay } \\
n=48\end{array}$ & $\begin{array}{c}\text { Baseline } \\
n=43\end{array}$ & $\begin{array}{c}\text { Tom Sawyer } \\
n=37\end{array}$ & $\begin{array}{c}\text { Simple Pay } \\
n=53\end{array}$ \\
\cline { 2 - 6 } Revealed Payoffs & 35 & 37 & 27 & 9 & 25 \\
& $(88 \%)$ & $(77 \%)$ & $(63 \%)$ & $(24 \%)$ & $(47 \%)$
\end{tabular}

Chose \$5, \$5 in Matrix 1

Total

$10 / 19 \quad 17 / 26 \quad 6 / 23$

$(53 \%) \quad(65 \%) \quad(27 \%)$

$3 / 18$

$7 / 27$

The

After revealing

$10 / 15 \quad 17 / 22 \quad 6 / 1$

$(67 \%) \quad(77 \%) \quad(44 \%)$

$3 / 6$

$(50 \%)$

$7 / 13$

$(54 \%)$ 